\title{
Probing Affinity, Avidity, Anticooperativity, and Competition in Antibody and Receptor Binding to the SARS-CoV-2 Spike by Single Particle Mass Analyses
}

\author{
Victor Yin, ${ }^{\nabla}$ Szu-Hsueh Lai, ${ }^{\nabla}$ Tom G. Caniels, Philip J. M. Brouwer, Mitch Brinkkemper, Yoann Aldon, \\ Hejun Liu, Meng Yuan, Ian A. Wilson, Rogier W. Sanders, Marit J. van Gils, and Albert J. R. Heck*
}

Cite This: ACS Cent. Sci. 2021, 7, 1863-1873

Read Online

ABSTRACT: Determining how antibodies interact with the spike (S) protein of the SARS-CoV-2 virus is critical for combating COVID-19. Structural studies typically employ simplified, truncated constructs that may not fully recapitulate the behavior of the original complexes. Here, we combine two single particle mass analysis techniques (mass photometry and charge-detection mass spectrometry) to enable the measurement of full IgG binding to the trimeric SARS-CoV-2 S ectodomain. Our experiments reveal that antibodies targeting the S-trimer typically prefer stoichiometries lower than the symmetry-predicted 3:1 binding. We determine that this behavior arises from the interplay of steric clashes and avidity

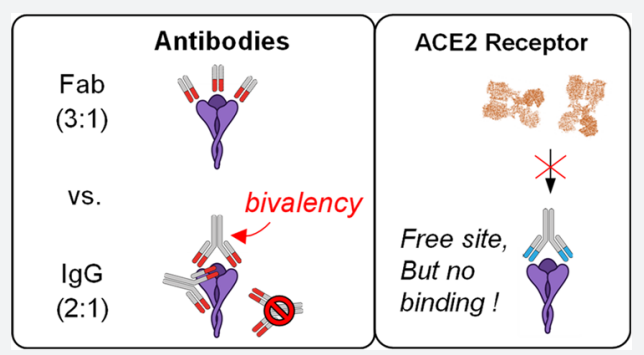
effects that are not reflected in common antibody constructs (i.e., Fabs). Surprisingly, these substoichiometric complexes are fully effective at blocking ACE2 binding despite containing free receptor binding sites. Our results highlight the importance of studying antibody/antigen interactions using complete, multimeric constructs and showcase the utility of single particle mass analyses in unraveling these complex interactions.

\section{INTRODUCTION}

The emergence of the SARS-CoV-2 coronavirus and subsequent onset of the coronavirus disease 2019 (COVID19) pandemic have necessitated the rapid development of vaccines and other treatments. ${ }^{1-3}$ The primary focus of these countermeasures is the SARS-CoV-2 spike (S) protein present on the viral surface, which is responsible for initiating host infection via complexation to the human ACE2 receptor and subsequent fusion of the viral and host cell membranes. ${ }^{4}$ The majority of vaccines developed against SARS-CoV-2 use the $S$ protein (e.g., genetically encoded via either mRNA/DNA cargo $^{5-7}$ or displayed on a nanoparticle surface ${ }^{8}$ ) to elicit an immune response. Understanding how exactly antibodies (Abs) interact with the SARS-CoV-2 $S$ protein is a crucial component for both continuing vaccine development as well as the rational design of target biotherapeutics (e.g., monoclonal Abs). ${ }^{9,10}$

Like the spike proteins of many other viruses, the SARS$\mathrm{CoV}-2 \mathrm{~S}$ protein is present in a trimeric, membrane-embedded state. ${ }^{11}$ Effective neutralizing Abs for SARS-CoV-2 often target the receptor binding domain (RBD) of the $S$ protein. ${ }^{12-15}$ As the RBD is the site of initial ACE2 receptor binding, these Abs are thought to achieve neutralization largely by sterically preventing interactions between the $S$ protein and host receptor. ${ }^{16}$ Due to its trimeric nature, each individual spike contains three copies of the RBD.

Given the central role of $\mathrm{Ab}$ binding for the successful neutralization of antigens, a seemingly simple question is how many copies of an Ab can bind to one spike? And relatedly, how many $\mathrm{Ab}$ copies need to bind to induce neutralization? Since each S-trimer contains three identical copies of the $S$ protomer, one may expect that Abs bind the S-trimer with a 3:1 stoichiometry. However, this prediction may be somewhat naive, and the true $\mathrm{Ab}$ binding stoichiometry will be complicated by several factors. First, the RBD is dynamic and can occupy either an "up" or "down" state, defined by its position relative to the remainder of the complex. ${ }^{11}$ Only the up RBD state is capable of binding the ACE2 receptor. ${ }^{17}$ As each $\mathrm{RBD}$ is related in the S-trimer by 3 -fold symmetry, there exists a total of 4 possible conformational states of the RBDs in the S-trimer (with up:down ratios of 0:3, 1:2, 2:1, and 3:0). Certain Abs against the RBD may only recognize one of the two states, which can interconvert. ${ }^{12,18,19}$ Therefore, any RBDtargeting $\mathrm{Ab}$ could conceivably bind a particular S-trimer with any stoichiometry between 0 and 3, depending on the exact conformational status of the complex. Second, full Abs (IgGs) possess two equivalent Fab arms, of which one or both may be involved in binding (i.e., avidity). Avidity effects are well-

Received: July 7, 2021

Published: November 4, 2021 
known to play key roles in the potency of neutralizing Abs and could manifest as an apparent decrease in binding stoichiometry. $^{20,21}$ Third, anticooperative binding effects arising from steric conflicts between multiple binding Abs may also play a role, hampering the amount of concurrent binding allowed.

Considering the known impacts that these various effects can have on $\mathrm{Ab}$ efficacy, the stoichiometries of $\mathrm{Ab}$ binding to the SARS-CoV-2 $S$ protein are surprisingly poorly characterized. This is likely due in part to the lack of biochemical and biophysical methods to effectively probe such heterogeneous interactions effectively and efficiently. For example, surface plasmon resonance (SPR) and biolayer interferometry (BLI) are highly effective at rapidly quantifying antigen binding but provide only an ensemble-averaged overview and yield limited structural information. ${ }^{22-24}$ Single particle electron microscopy (EM) can often provide near-atomic details of protein structure and protein-protein interactions, allowing direct mapping of $\mathrm{Ab}$ epitopes on the full SARS-CoV-2 $\mathrm{S}$ ectodomain. ${ }^{11,25-27}$ However, due to the extended flexibility of full-length IgGs, EM is typically (with some exceptions ${ }^{28}$ ) only able to visualize binding of antibody fragments (i.e., truncated Fab domains) and thus may not directly capture any effects of avidity or steric interactions that would occur in the full IgG. Nuclear magnetic resonance spectroscopy and X-ray crystallography can yield atomic protein structures but, due to limitations with size and conformational/glycosylation-induced heterogeneity, respectively, have been largely restrained to studies on truncated single RBD constructs and thus remain relatively blind to both the up:down dynamics of the full trimer as well as potential avidity effects. ${ }^{29,30}$

Native mass spectrometry (MS) is an analytical technique capable of measuring the mass of proteins and protein complexes. ${ }^{31}$ As any binding event leads to a corresponding increase in mass, native MS offers a convenient readout of ligand binding and can readily distinguish different binding stoichiometries and different ligands by their unique masses. In the context of monitoring interactions to the SARS-CoV-2 S protein, the feasibility of these experiments is greatly hindered by the extreme heterogeneity caused by the high degree of glycosylation present on the $S$ protein (the so-called glycan shield). ${ }^{32-34}$ This heterogeneity leads to a normally untenable degree of spectral complexity that obfuscates the charge state assignments required for correct mass determination. ${ }^{33}$ While some success has been reported in the conventional native MS analysis of SARS-CoV-2 $S$ and other viral spike proteins (e.g., by metabolic glycan engineering ${ }^{36}$ or limited charge reduction $^{37}$ of truncated constructs), these modified constructs may not exhibit the same binding behavior as the real viral spike protein, given the known importance of glycan structure in these interactions. ${ }^{32}$

Here, we report the application of two single particle approaches for mass analysis, mass photometry, ${ }^{38}$ and chargedetection native mass spectrometry, ${ }^{39,40}$ to circumvent the need of conventional charge assignment and allow successful measurement of the full SARS-CoV-2 S-trimer ectodomain, as well as the binding stoichiometries to full-length neutralizing IgGs. Our measurements reveal that IgG binding to the SARSCoV-2 S-trimer can exhibit a diversity of binding behaviors that are not captured when studying the truncated Fabs or $\mathrm{RBD}$ constructs alone. We also demonstrate that these techniques can be used to monitor binding of the ACE2 receptor, as well as the $S$ proteins from other variants of concern of the SARS-CoV-2 virus. These ultrasensitive single particle approaches (requiring only $\sim$ femtomoles of sample) thus offer a powerful addition to the toolkit of contemporary biophysical tools by providing a "one-shot" method for determining $\mathrm{Ab}$ affinity, anticooperativity, and avidity simultaneously. Our findings highlight the biophysical complexity of the multimeric interactions that occur between $\mathrm{Abs}$ and the SARS-CoV-2 S protein.

\section{RESULTS AND DISCUSSION}

Single Particle Mass Analysis of the SARS-CoV-2 STrimer. Originally introduced as interferometric scattering mass spectrometry (iSCAMS), ${ }^{38}$ mass photometry (MP) is a light scattering-based, label-free, mass analysis technique that determines the mass of a single particle in solution from its scattering intensity. ${ }^{41}$ Since MP does not rely on any charge state determination, the masses of extensively glycosylated proteins can be readily measured. Advantages of MP include its rapid analysis time and a minimal need of sample preparation. A representative MP histogram of the SARS-CoV-2 S-trimer is depicted in Figure 1A. The S-trimer exhibits a large primary
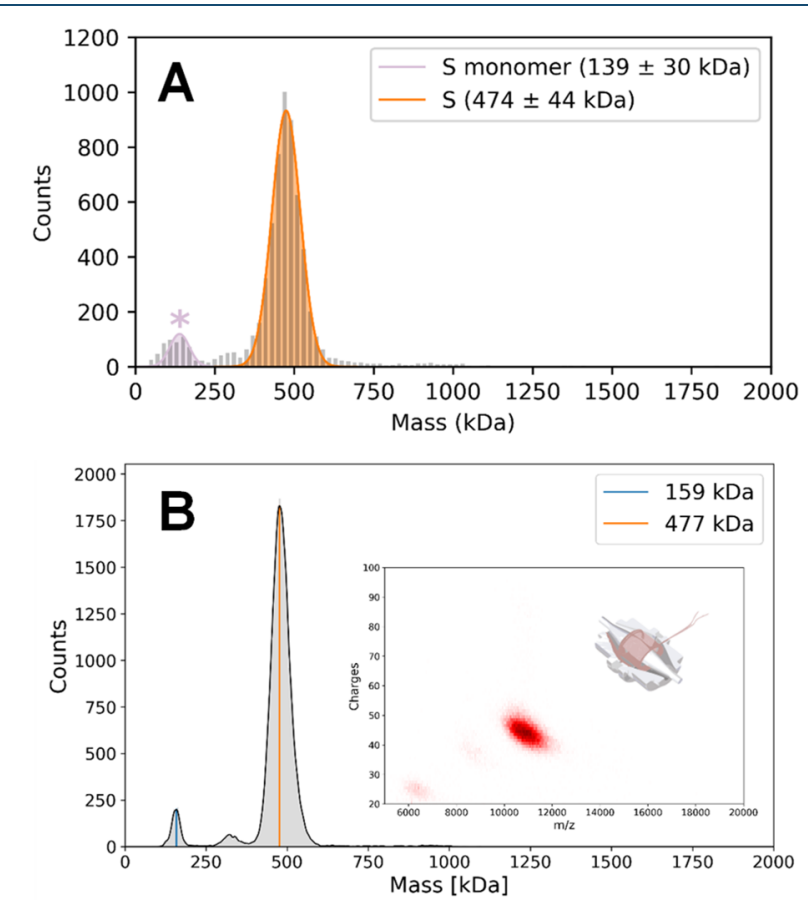

Figure 1. Representative mass histograms of the SARS-CoV-2 Strimer. (A) MP histogram. (B) 1D CD-MS histogram, with the 2D CD-MS histogram shown in the inset. The measured masses and abundances related to these data are provided in Table S1. In both cases, the S-trimer is the predominant species, with a minor contribution of $\mathrm{S}$-monomer. A low population of particles corresponding to S-dimer $(\sim 300 \mathrm{kDa})$ could also be detected. The total concentration of S-trimer is $100 \mathrm{nM}$.

distribution at $474 \mathrm{kDa}$, while a minor low-mass distribution is also observed and can be assigned as residual S-monomer. Of note, no species corresponding to higher-order aggregates (i.e., dimers of S-trimers ${ }^{25}$ ) are observed.

Alternatively, charge-detection mass spectrometry (CD-MS) can be used to overcome the charge inference problem in native MS by directly detecting both the charge and mass-tocharge $(\mathrm{m} / \mathrm{z})$ ratio of an ion. ${ }^{42}$ Due to this two-dimensional detection method, peaks that are unresolved in the $\mathrm{m} / z$ 

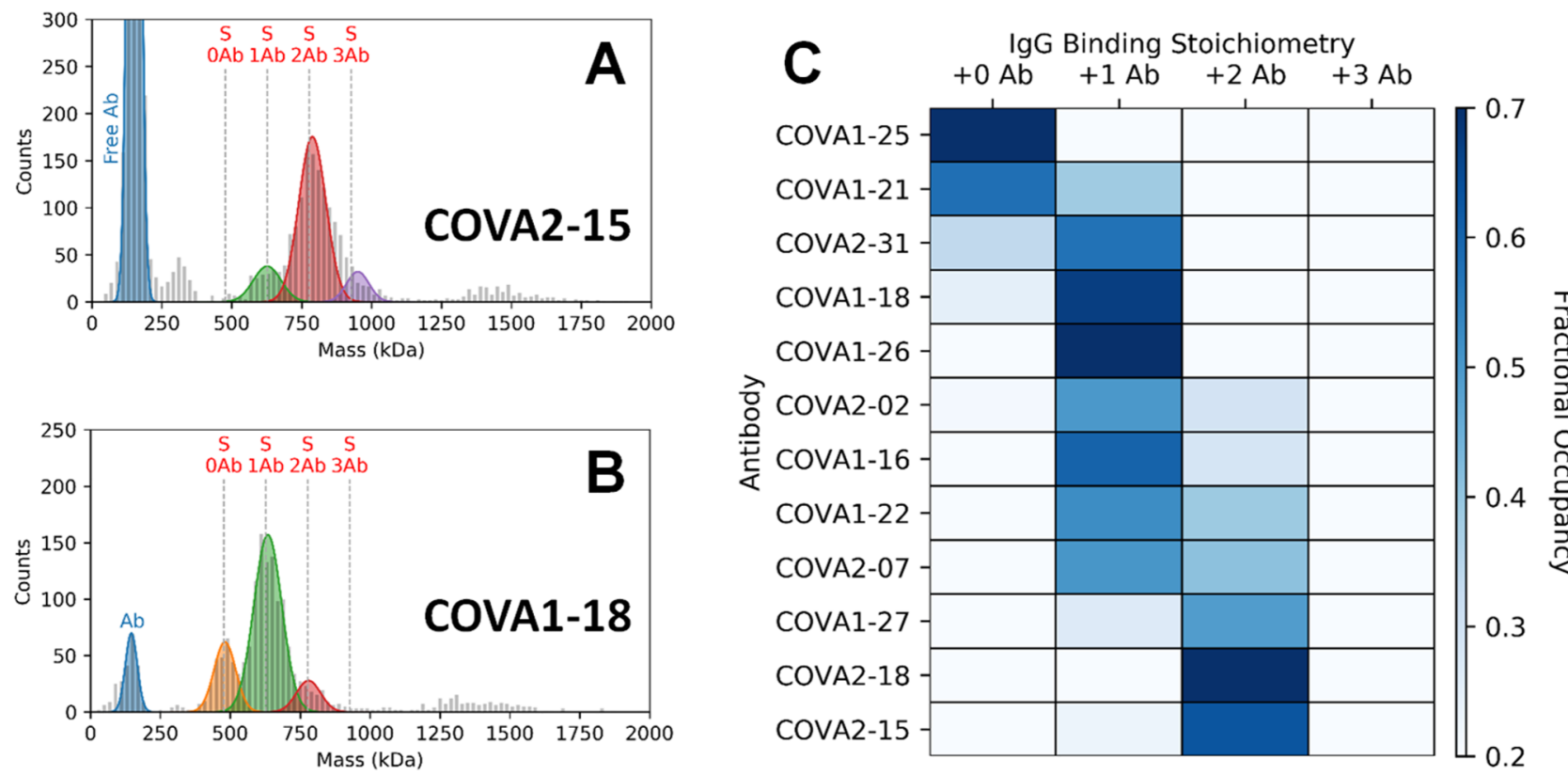

Figure 2. Measurement of IgG binding stoichiometries to the S-trimer by MP. MP histograms of the S-trimer following incubation with (A) COVA2-15 or (B) COVA1-18. The vertical dashed lines indicate the theoretical peak positions of each IgG-bound species. MP histograms of each of the Abs alone show a single major distribution at $\sim 150 \mathrm{kDa}$, in line with the expected IgG mass (Figure S2). The data clearly reveal that the "complete" 3:1 binding is not achieved for either Ab. COVA2-15 preferably binds two IgGs, whereas just one COVA1-18 binds to the S-trimer. Increasing concentrations of $\mathrm{Ab}$ do not change the preferred binding stoichiometries (Figure S3). Binding of both Abs to the S-trimer was also measured by CD-MS, and very similar binding behavior was observed, further illustrating the complementarity between MP and CD-MS (Figure S4). The low-abundance signals observed between 1200 and $1600 \mathrm{kDa}$ originate from Ab-binding-induced S-trimer dimers. (C) Fractional occupancies of each IgG-bound S-trimer species for a panel of 12 monoclonal Abs. A large diversity of binding stoichiometries are observed, ranging from 0 to 2 . None of the tested Abs exhibited a preference for 3:1 binding. Additional representative MP histograms are depicted in Figure S1. A tabulation of binding stoichiometries related to these data are provided in Table S2. The concentration of S-trimer in each measurement is 50 $\mathrm{nM}$.

dimension may still be resolvable in the charge dimension, aiding in the assignment of complex spectra. In contrast to the solution-based measurements of MP, CD-MS measurements are performed on particles following their ionization and introduction into the gas phase. Over the years, a body of evidence has been accumulated demonstrating that protein complexes can be mass analyzed in the gas phase while generally retaining their native stoichiometry and other aspects of higher-order structure. ${ }^{43}$ The similar results here obtained by MP and native CD-MS support the validity of the presented findings and the absence of measurement biases.

A representative Orbitrap-based CD-MS histogram of the SARS-CoV-2 S-trimer is depicted in Figure 1B. Again, a single major distribution of particles corresponding to the S-trimer is observed, with a minor distribution corresponding to the Smonomer also detected. The higher mass resolution achievable by CD-MS (as exhibited by the narrower mass distributions of the S-trimer relative to MP) highlights an important advantage of CD-MS. The trimer mass measured by CD-MS (477 kDa) is within $\sim 1 \%$ of the mass determined by MP. The close agreement in the results of these two disparate single particle methods underscores the robustness and complementarity of these approaches.

The backbone sequence-predicted mass of the S-trimer construct used here $(390.349 \mathrm{kDa})$ underestimates the observed mass measured by both techniques by $\sim 90 \mathrm{kDa}$, reflecting the extensive glycosylation profile of the $S$ protein. To estimate the expected mass contribution of the glycan shield, we calculated the average $\mathrm{N}$-glycan masses derived from the glycoproteomic data of Allen and co-workers. ${ }^{44}$ The calculated glycan $(92.0 \mathrm{kDa})$ and resultant total S-trimer $(482.4 \mathrm{kDa})$ masses agree quite well (within $2 \%$ ) with the masses measured by both MP and CD-MS. The glycan mass contribution measured here is somewhat lower than the recent results of Miller and co-workers ${ }^{45}$ who reported large mass discrepancies of $\sim 40 \%$ from similar glycoproteomic experiments. However, it should be noted that the constructs used in that study differ from the one employed here in several key aspects (e.g., absence of stabilizing $2 \mathrm{P}$ mutations, different expression systems, etc.), as well as differing substantially in experimental setup (electrostatic linear ion trap vs Orbitrap), which all may be factors accounting for this apparent discrepancy.

Abs Targeting the S-Trimer Can Exhibit Diverse Binding Characteristics. To establish the capability of single particle mass measurements to resolve the binding of Abs to the S-trimer, we initially screened the binding of a representative panel of 12 monoclonal anti-S-trimer IgGs using MP (Figure 2). These previously reported Abs, originally isolated from the sera of convalescent COVID-19 patients, target a variety of epitopes and exhibit varying neutralization potencies (Table S3). ${ }^{12}$ Upon incubation of the S-trimer with the IgGs, new species of larger mass in the MP histograms are readily observed (Figure 2A,B, Figure S1). The evenly spaced, successive mass shifts of $\sim 150 \mathrm{kDa}$ correspond to the binding of 1,2 , and 3 intact IgGs to the S-trimer. The particle distributions for each of the Abs are summarized as a heat map in Figure 2C.

Our measurements reveal that Abs targeting the S-trimer can bind with a variety of preferred stoichiometries. Interestingly, 
Ratio

COVA2-15 Fab
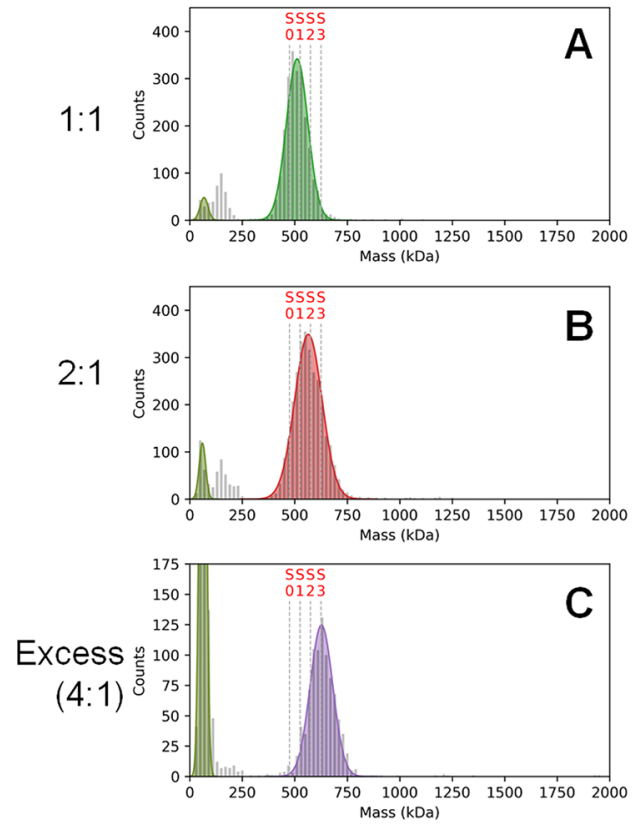
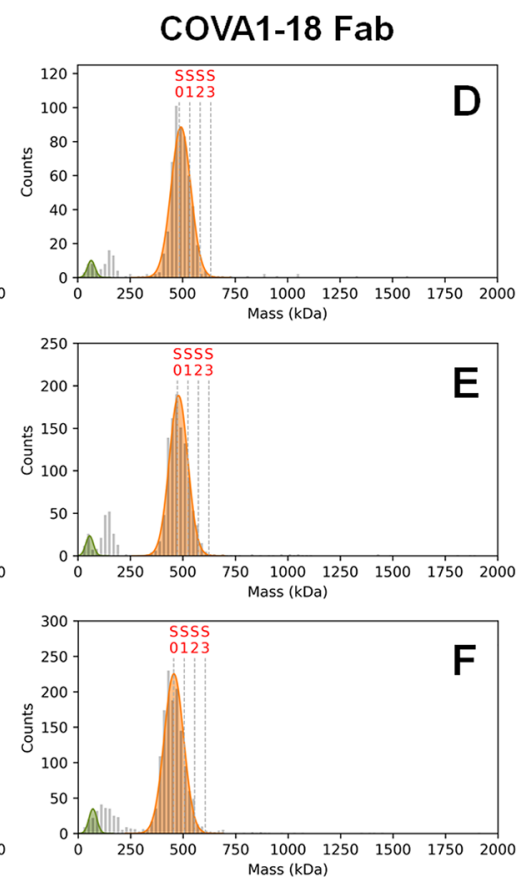
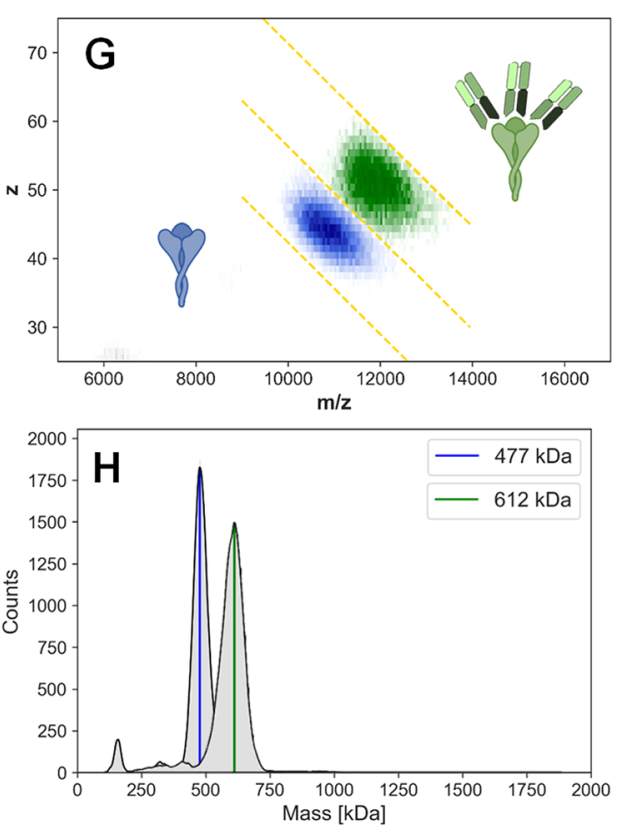

Figure 3. Stoichiometry of Fab binding to the S-trimer. (A-F) MP histograms of COVA2-15 and COVA1-18 Fab binding to the SARS-CoV-2 Strimer at different mixing ratios. The vertical dashed lines indicate the theoretical peak positions of each Fab-bound stoichiometry. The data reveal that the S-trimer readily binds 3 COVA2-15 Fabs, whereas even in excess not a single COVA1-18 Fab binds to the S-trimer. (G, H) 2D and 1D CD-MS histograms of COVA2-15 Fab binding with excess ratio of Fab (green) as well as SARS-CoV-2 S-trimer only (blue). The observed shift in mass of $\sim 135 \mathrm{kDa}$ confirms that the S-trimer predominantly binds 3 COVA2-15 Fabs. The concentration of S-trimer in each measurement is 50 $\mathrm{nM}$.

none of the tested Abs exhibited a preference for the "complete" 3:1 (IgG:S-trimer) stoichiometry given the symmetry of the S-trimer. One may predict that these binding differences simply reflect different affinities of each Abs. Indeed, the two tested Abs with the lowest observed binding stoichiometries (COVA1-25 and COVA1-21) also have the weakest reported apparent dissociation constant $\left(K_{\mathrm{D} \text {,app }}\right)$ values $(\gg 10 \mathrm{nM})$, and both exhibit a large proportion of free $S$ trimer. The remaining Abs, however, are quite similar in their affinities, with $K_{\mathrm{D} \text {,app }}$ values all in the sub-nM range (Table S3). While COVA2-31, COVA1-18, COVA1-26, COVA2-02, COVA1-16, COVA1-22, and COVA2-07 preferably bound with a 1:1 stoichiometry, the dominant stoichiometry for COVA1-27, COVA2-18, and COVA2-15 was 2:1. The observation of diverse binding stoichiometries among the tested Abs, despite their very similar (and potent) $K_{\mathrm{D} \text {,app }}$ values, rules out affinity differences as the main driver of the remaining binding stoichiometries.

To help delineate other factors that may be modulating these stoichiometries, we next produced and evaluated Fab fragments and measured their binding to the S-trimer. Unlike the IgGs of each $\mathrm{Ab}$, Fabs are only capable of binding one copy of an antigen (i.e., no avidity effects are possible), and due to their smaller size, the contributions of steric clashes on the observed binding behavior are minimal. These Fab experiments closely mimic previously reported analyses performed by single particle EM, where binding of Fab fragments was monitored. ${ }^{11,25-27}$ It is important to emphasize that while Fab fragments can clearly serve as a useful in vitro analogue, it is the intact IgG that is the biologically relevant species during the human immune response.

COVA2-15 and COVA1-18. For these subsequent investigations, we focus specifically on two Abs: COVA2-15 and COVA1-18. These Abs, which both target epitopes on the $\mathrm{RBD}$, were chosen first for their clinical relevance as both are among the most highly potent among the tested Abs in neutralizing the Wuhan SARS-CoV-2 strain, possessing nearidentical neutralization potencies $\left(\mathrm{IC}_{50} \sim 0.008 \mu \mathrm{g} / \mathrm{mL}\right){ }^{12}$ COVA1-18 has also been shown to protect cynomolgus macaques from high-dose SARS-CoV-2 challenge. ${ }^{10}$ Second, despite these similar efficacies, our results indicate that these two Abs exhibit quite distinct (and representative) binding stoichiometries: COVA2-15 exhibits a preference for a 2:1 stoichiometry (with particles corresponding to 1,2 , or 3 bound IgGs, Figure 2A), whereas COVA1-18 displays a preference for 1:1 binding (with particles corresponding to 0,1 , or 2 bound IgGs, Figure 2B). In other words, the binding stoichiometries of these two Abs appear uncorrelated to both affinity and neutralization potency.

The binding behaviors of the COVA1-18 and COVA2-15 Fabs differ substantially from those of their corresponding IgGs. When added in excess, the clearly observed mass shift reveals a preference for 3:1 binding for the COVA2-15 Fab by both MP (Figure 3C) and CD-MS (Figure 3G,H) - greater than the 2:1 seen for the full IgG. This stoichiometry agrees well with recent EM structures of the S-trimer bound to COVA2-15 Fabs, in which electron density for three bound Fabs was reported, and is in line with all three RBD copies of the S-trimer being occupied. ${ }^{12}$ Titration of COVA2-15 Fab at lower concentrations produces species of intermediate mass, corresponding to binding stoichiometries lower than 3:1 (Figure 3A,B). Interestingly, the COVA1-18 Fab exhibited essentially no binding to the $S$-trimer even when added in excess (Figure 3F), in contrast to the COVA1-18 IgG that revealed 1:1 binding (Figure 2B). This poor binding may explain why previous attempts to obtain a cryo-EM structure of 


\begin{tabular}{|c|c|cc|}
\hline \multicolumn{2}{|c|}{ COVA1-18 } & \multicolumn{2}{c|}{ COVA2-15 } \\
\hline A B & B & C & \\
\hline $\begin{array}{c}\text { Fab } \\
\text { No Binding }\end{array}$ & IgG & Fab & IgG \\
\hline
\end{tabular}

Figure 4. Proposed binding modes of COVA1-18 and COVA2-15 to the S-trimer. (A) For COVA1-18, its Fab has too low an affinity to effectively bind the S-trimer (violet). (B) In its native IgG format, bivalent interactions of the two Fabs enable effective binding with a dominant stoichiometry of 1:1. (C) For COVA2-15, its Fab possesses sufficient affinity alone to bind the S-trimer and occupies all three binding sites due to the lack of steric interactions. While the COVA2-15 IgG should theoretically be able to also bind with a 3:1 ratio, a combination of steric clashes (D) and/or bivalent binding (E) prevents this stoichiometry from being preferred.

COVA1-18 with the S-trimer using Fabs were unsuccessful (Andrew Ward, personal communication).

What is the root cause of the divergent binding behaviors between both of the different Abs, as well as between the IgGs and their associated Fabs? As described above, this could arise from several competing factors. For example, one may envision that the $\mathrm{Ab}$ binding stoichiometries could be simply reporting on the relative RBD up:down ratios in the S-trimer. Cryo-EM studies have suggested that the predominant states of the $S$ trimer are likely the $\left[0\right.$ up:3 down] and $\left[\begin{array}{lll}1 & \text { up: } 2 \text { down] }\end{array}\right.$ configurations. $^{11}$ While this hypothesis has some qualitative agreement with the observed IgG binding stoichiometries (e.g., COVA1-18 would recognize the single "up" RBD state, ${ }^{12}$ so a $1: 1$ stoichiometry is expected), it cannot satisfactorily rationalize either (1) the 2:1 binding seen in the COVA2-15 IgG (which binds agnostically to both "up" and "down" states ${ }^{12}$ ) or (2) the different binding behavior between the IgGs and Fabs. Evidently, other factors must also play a key role.

In the case of COVA1-18, the Fab displays substantially less binding than its corresponding IgG. This dramatic affinity loss going from intact IgG to Fab fragment is a hallmark of avidity (bivalent interactions). ${ }^{21,26,46}$ The possibility of avidity in the neutralization potency of COVA1-18 has recently been suggested, with measured $K_{\mathrm{D}}$ and pseudovirus $\mathrm{IC}_{50}$ values of the Fab more than 1 and 2 orders of magnitude worse, respectively, when compared to the full $\mathrm{IgG}^{10}$ In the context of viral spike proteins, the bivalent IgGs can theoretically bind in two distinct modes: interspike (bridging between two different spike trimers) or intraspike (binding two domains on the same spike). ${ }^{21}$ Although recent studies have shown that bivalent binding of IgGs likely has a significant effect on the interaction and neutralization abilities of several SARS-CoV-2 antibodies, ${ }^{28,46-50}$ the direct structural characterization of binding stoichiometries has not previously been reported due to the conformational flexibility of the IgG hinge regions. While it is possible to infer the general presence of avidity effects using prevailing biochemical assays (e.g., comparing antibody binding on immobilized monomeric RBD vs trimeric $S$ by $\mathrm{SPR}^{28}$ ), distinguishing between the different binding modes in these measurements is also not straightforward. By comparison, the mass measurements presented here readily allow differentiation of the two scenarios by their unique stoichiometries: intraspike binding will produce Ab-bound species containing only one S-trimer, whereas interspike binding will produce species that will contain two S-trimers.
Returning to Figure 2, the prominence of the $[S+1 \mathrm{Ab}]$ species suggests that the intraspike binding mode is the more prevalent mode for COVA1-18, although some signals in the $1200-1600 \mathrm{kDa}$ range can be observed (which are absent in both the isolated S-trimer and in the presence of Fabs), suggesting that a minor contribution of interspike binding is also possible. The lower-than-expected 1:1 binding stoichiometry seen in the COVA1-18 IgG then likely corresponds to a single $\mathrm{Ab}$ occupying two $\mathrm{RBD}$ binding sites on a single $\mathrm{S}$ trimer due to bivalent binding (Figure 4B). Higher binding stoichiometries may then be inhibited due to the single available $\mathrm{RBD}$ site remaining (i.e., intraspike binding is no longer possible).

For COVA2-15, the scenario is different as its Fab shows a higher binding stoichiometry than its corresponding IgG. One possibility is that binding of an initial IgG hampers the subsequent binding of additional IgGs (i.e., anticooperativity, Figure 4D). Considering that the smaller COVA2-15 Fab readily binds with the full 3:1 stoichiometry, the most likely source of this behavior in this scenario would be steric clashes arising from the full IgG(s) that occlude the COVA2-15 IgG from fully occupying all three RBD sites. An alternative possibility is that COVA2-15, like COVA1-18, may also be capable of S-trimer binding via intraspike cross-linking. In this scenario, one COVA2-15 IgG would bind bivalently to two RBD sites, while the remaining RBD site is occupied by a second, monovalently bound IgG (Figure 4E). This arrangement would also appear as a 2:1 binding stoichiometry, albeit with a different spatial configuration. Unlike COVA1-18, where avidity is a prerequisite for binding, in this arrangement COVA2-15 would seemingly not depend on this avidity to maintain affinity for the S-trimer, as evidenced by the binding capability of the COVA2-15 Fab (Figure 3A-C). Given that a small population of a $3: 1$ stoichiometry is observed for the COVA2-15 IgG (Figure 2A), it is likely that there exists a contribution of Fab-like, "monovalent-only" binding (Figure 4D) even if bivalent binding is the dominant binding mode (Figure 4E). Taken together, these results highlight the rich complexity inherent to IgG-S-trimer interactions, and the capacity of single particle analyses to aid in unraveling this complexity.

Substoichiometric IgG Binding Is Sufficient to Prevent ACE2 Binding. Given that COVA1-18 (and perhaps also COVA2-15) appears to leave at least one RBD site unoccupied, one may wonder if these $\mathrm{Ab}$-bound $\mathrm{S}$-trimers are 

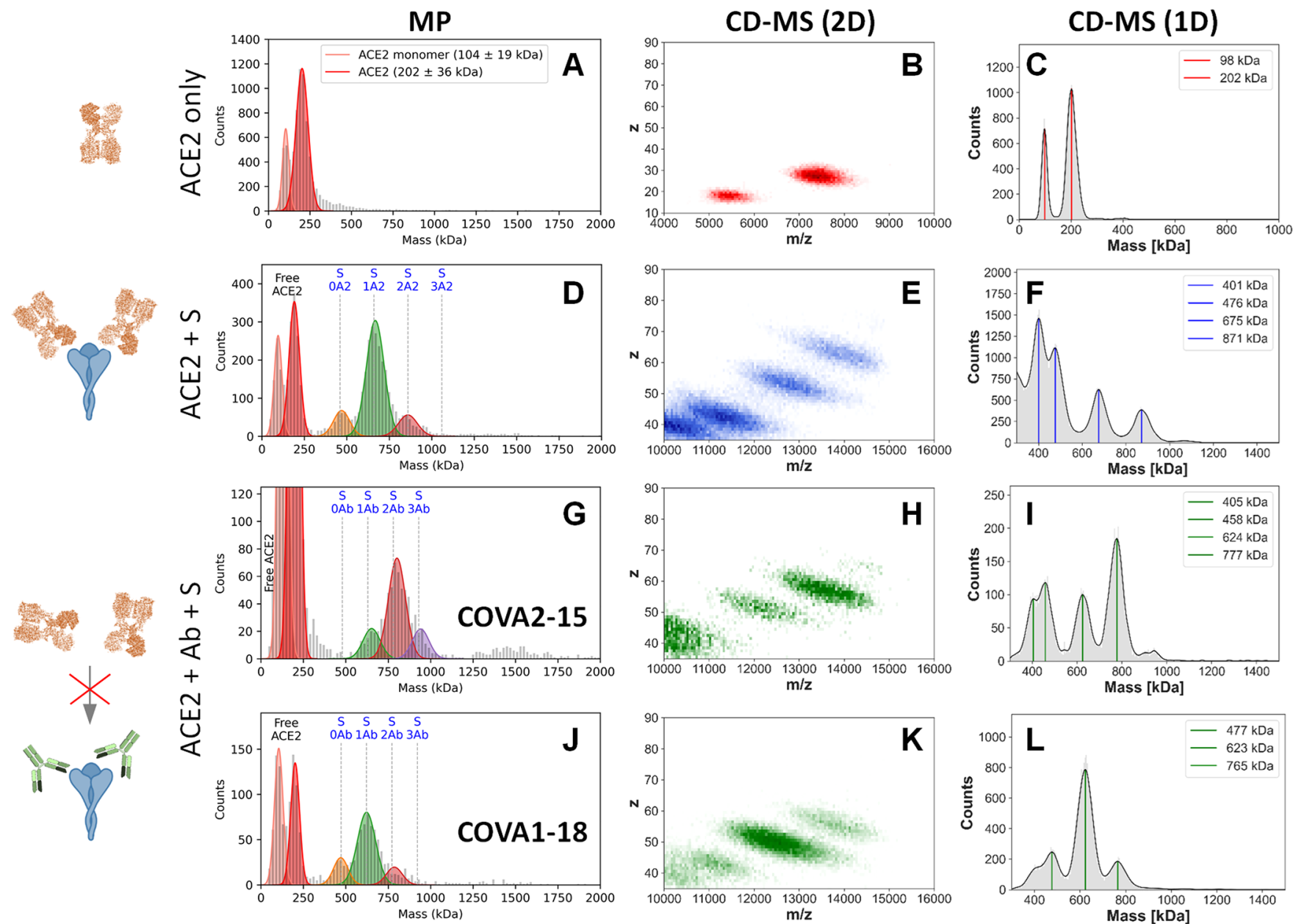

Figure 5. Substoichiometric $\mathrm{Ab}$ binding to the S-trimer is sufficient to neutralize receptor binding. (A-C) MP and CD-MS histograms of ACE2 alone, revealing the dimeric nature of the utilized ACE2 construct and (D-F) ACE2 binding to the S-trimer. These results show that ACE2 is largely dimeric, and only the ACE2-dimer binds to S-trimer, whereby the S-trimer can accommodate either one or two ACE2. (G-L) MP and CDMS histograms of ACE2 binding to the S-trimer following preincubation with either (G-I) COVA2-15 or (J-L) COVA1-18. The observed mass shifts of $\sim 150 \mathrm{kDa}$ (and not $200 \mathrm{kDa}$ ) indicate that both Abs fully prevent ACE2 binding to the S-trimer. Mixing ratios of 4:1 and 4:4:1 (ACE2dimer:S-trimer and Ab:ACE2-dimer:S-trimer, respectively) were used for the CD-MS experiments, while 1:1 and 3:1:1 were used for the MP experiments. Note the similarities between the data presented in panel G and Figure 2A, and panel J and Figure 2B.

still capable of binding the S-trimer host-receptor, ACE2. To explore this, we measured the binding of the ACE2 ectodomain against the $S$-trimer in the presence or absence of either the COVA1-18 or COVA2-15 IgG (Figure 5). ACE2bound $\mathrm{S}$-trimer species are distinguishable from their $\mathrm{Ab}$ bound analogues by the different masses of the ACE2-dimer (200 kDa; Figure 5A-C) and an IgG (150 kDa; Figure S2). In the absence of any $\mathrm{Ab}$, the S-trimer readily binds ACE2, with a predominant 1:1 stoichiometry at low mixing ratios as detected by MP (Figure 5D). MP measurements at higher ACE2 concentrations were partially impeded by spectral interference caused by a subpopulation of a tetrameric ACE2 state which is of comparable mass to the free S-trimer ( $\sim 400$ vs $477 \mathrm{kDa})$, although the species corresponding to ACE2-bound S-trimers remain unobstructed (Figure S5). While these species were also detected by CD-MS (and remain partially unresolved in the mass domain), the two species can be readily delineated in the $2 \mathrm{D}$ CD-MS histogram by their differences in both charge and $m / z$ (Figure $5 \mathrm{E}, \mathrm{H}, \mathrm{K}$ ), highlighting the added potential of CD-MS to aid in interpreting spectrally congested data sets. The binding stoichiometries observed here using a nativelike dimeric ACE2 construct are lower than the 3:1 stoichiometry of a monomeric ACE2 construct seen in a recently reported cryo-EM structure, ${ }^{51}$ once again highlighting the central role of oligomeric state on the nature of these interactions.

In contrast to the clear observed binding of ACE2 in the absence of $\mathrm{Ab}$, preincubation of the S-trimer with either the COVA2-15 or COVA1-18 IgG prior to the addition of ACE2 produces only IgG-bound species, with no species observed corresponding to ACE2 binding, neither by formation of ternary $[S$-trimer $+\mathrm{Ab}+\mathrm{ACE} 2]$ complexes nor via displacement of bound $\mathrm{Ab}$ (Figure $5 \mathrm{G}, \mathrm{I}, \mathrm{J}, \mathrm{L}$ ). It is likely that the same factors preventing the IgGs from reaching the "full" 3:1 stoichiometry (e.g., steric clashes and/or avidity effects) are preventing ACE2 from binding as well. Despite the seemingly available RBD site(s), it appears that substoichiometric IgG binding is sufficient to fully block ACE2 binding, rendering them ideal neutralizing antibodies.

Virus Variants of Concern. There is ongoing concern that newly emerging strains of the SARS-CoV-2 virus harboring additional mutations in the $S$ protein may negatively impact the potency of already-existing anti-SARS-CoV-2 monoclonal Abs. ${ }^{50,52-54}$ As a proof-of-concept, we measured the binding of COVA2-15 and COVA1-18 against an S-trimer protein 
construct harboring the mutations present in the B.1.351 strain that originated in South Africa (Figure 6). In stark contrast to
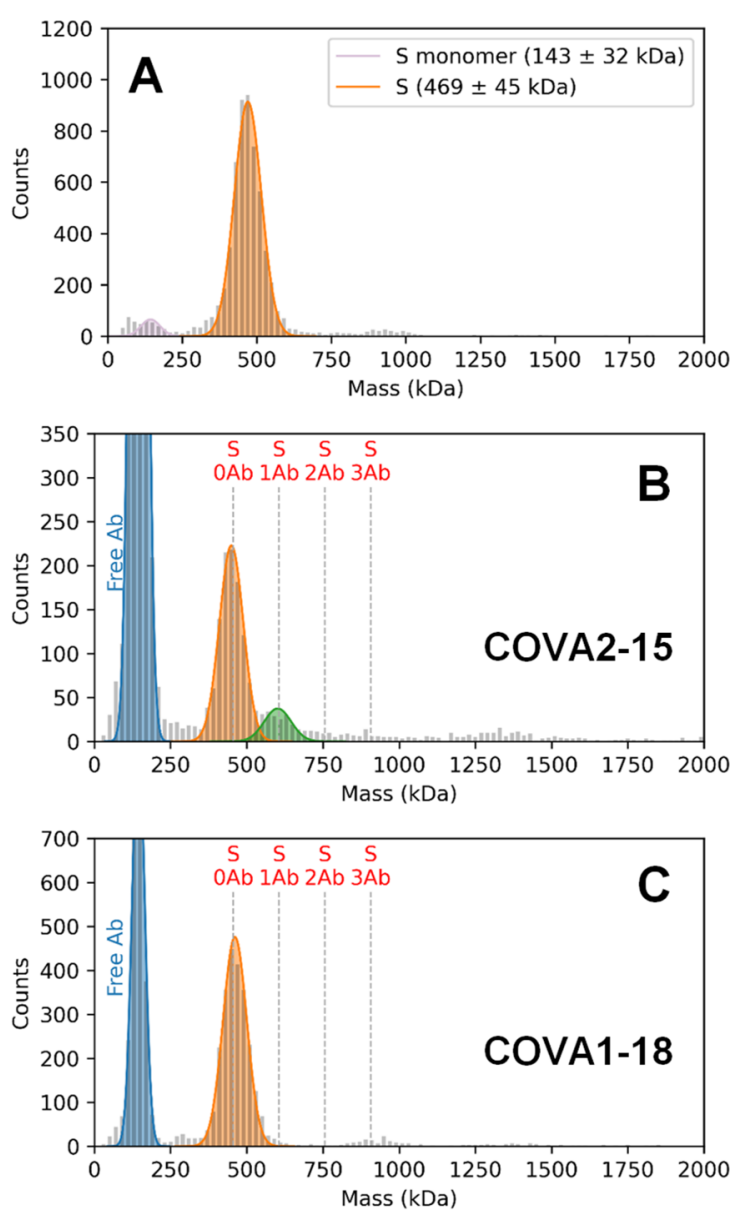

Figure 6. MP histograms of COVA2-15 and COVA1-18 binding to the SARS-CoV-2 variant N501Y.V2 S-trimer. (A) Variant S-trimer alone. S-trimer incubated with (B) COVA2-15 or (C) COVA1-18. In stark contrast to the original lineage (Figure 2), essentially no $\mathrm{Ab}$ binding is observed.

the original lineage, both Abs show substantially lower binding to this variant, with COVA1-18 exhibiting essentially no affinity. This binding loss is expected as COVA1-18 is unable to neutralize B.1.351, while COVA2-15 has substantially reduced activity. ${ }^{10,55}$ These results strengthen the arguments for the necessity of using multiple Abs (cocktails) for the design of target biotherapeutic treatments and also highlight the potential of mass photometry and charge-detection mass spectrometry to guide $\mathrm{Ab}$ design and development.

\section{CONCLUSIONS}

We demonstrate here the unique application of two single particle approaches, MP and CD-MS, for interrogating the interaction stoichiometries between full Abs, the ACE2 receptor, and the SARS-CoV-2 S protein ectodomain. We find that different Abs can exhibit surprisingly distinct binding behavior. In the case of the potent neutralizing Abs COVA2-15 and COVA1-18, different binding stoichiometries can arise despite commonly targeting the RBD and having identical neutralization potencies. This behavior is not fully recapitulated when analyzing the binding of Fab fragments, stressing the necessity of studying $\mathrm{Ab}$-antigen interactions in the context of the full, nontruncated IgG. Our results highlight the complex interplay of affinity, avidity, and anticooperativity effects in these interactions and the capability of single particle mass analysis to shed light on these cooccurring phenomena.

Our analyses here focus primarily on the binding behavior of the two representative neutralizing Abs COVA2-15 and COVA1-18. One may wonder if the determinants of the $1: 1$ and 2:1 binding behavior that we uncovered for these Abs can be generalized to other anti-S-trimer Abs (e.g., Figure 2C). While it is tempting to speculate, for example, that all $1: 1$ binding IgGs bind in a manner analogous to COVA1-18 (i.e., bivalently), in reality, the situation may be more complex. Other factors such as steric blockage, incompatible angles of approach, or the location of the epitope cannot be dismissed $a$ priori. As such, the binding determinants of each $\mathrm{Ab}$ should be determined on a case-by-case basis. Nevertheless, the experimental approaches outlined in this work, especially in combination with already-established methods such as single particle EM, are well-suited to address these questions.

Our investigations were enabled by the capacity of recently developed single particle approaches to overcome the high degree of mass spectral complexity normally brought by the extensive glycosylation of the SARS-CoV-2 S protein. We expect that these technologies will open the door for studies into similarly complex biological systems, such as glycoproteins from other viruses and biological agents. We foresee that these techniques will be especially useful in the characterization and rational design of biotherapeutics, e.g., monoclonal $\mathrm{Ab}$ cocktails or multivalent nanobodies. ${ }^{56,57}$ It is anticipated that single particle mass analysis will provide a powerful addition to the toolbox of contemporary biophysical methods to study protein-protein interactions.

\section{MATERIALS AND METHODS}

WT and B.1.351 Spike Proteins, Human ACE2 Receptor, and Antibodies. The 2P-stabilized S proteins of the Wuhan strain (WT) and B.1.351 variant were described previously. ${ }^{12,55}$ The B.1.351 construct contained the following mutations compared to the WT variant (Wuhan $\mathrm{Hu}-1$; GenBank: MN908947.3): L18F, D80A, D215G, L242H, R246I, K417N, E484K, N501Y, D614G, and A701V. Both S constructs were produced in HEK293F suspension cells (ThermoFisher) and purified as previously described. ${ }^{12}$ For the human ACE2 receptor, soluble ACE2 was generated as described previously ${ }^{12}$ by using a gene encoding amino acids 18-740 of ACE2. The IgGs and Fab fragments used in this study were produced as previously described. ${ }^{12,26}$

Mass Photometry. MP experiments were performed on a Refeyn OneMP (Refeyn Ltd.). Microscope coverslips (24 mm $\times 50 \mathrm{~mm}$; Paul Marienfeld $\mathrm{GmbH}$ ) were cleaned by serial rinsing with Milli-Q water and HPLC-grade isopropanol (Fisher Scientific Ltd.), on which a CultureWell gasket (Grace Biolabs) was then placed. For each measurement, 12 $\mu \mathrm{L}$ of buffer was placed in the well for focusing, after which 3 $\mu \mathrm{L}$ of sample was introduced and mixed. Movies were recorded for $120 \mathrm{~s}$ at $100 \mathrm{fps}$ under standard settings. MP measurements were calibrated using an in-house prepared protein standard mixture: IgG4 $\Delta$ hinge-L368A (73 $\left.\mathrm{kDa}^{58}\right)$, IgG1-Campath (149 $\mathrm{kDa})$, apoferritin $(479 \mathrm{kDa})$, and GroEL $(800 \mathrm{kDa})$. MP data were processed using DiscoverMP (Refeyn Ltd.). Peaks for each mass species were manually identified and fitted using SciPy. ${ }^{59}$ All MP histograms were plotted using $20 \mathrm{kDa}$ bin widths. 
All MP measurements were performed in Tris buffer [25 mM Tris, $100 \mathrm{mM} \mathrm{NaCl}$, pH 7.6 (Sigma-Aldrich)]. For each experiment, a $100 \mathrm{nM}$ solution of SARS-CoV-2 S protein was mixed with an equal volume of ligand to the desired concentration ratio and incubated at room temperature (22 ${ }^{\circ} \mathrm{C}$ ) for $5 \mathrm{~min}$. Longer incubation times (up to $75 \mathrm{~min}$ ) were also tested, with no major differences in binding stoichiometries observed (Figure S6). Unless otherwise stated in the text, ligands were mixed at a 3:1 (ligand:S-trimer) molar ratio. Afterward, $3 \mu \mathrm{L}$ of the reaction mixture was immediately transferred to the instrument for measurement. For binding experiments containing both $\mathrm{Abs}$ and $\mathrm{ACE} 2, \mathrm{~S}$ protein was preincubated with $\mathrm{Ab}$ for $5 \mathrm{~min}$ as described above, after which an equal volume of ACE2 solution at the desired concentration was added and incubated for a further $5 \mathrm{~min}$ prior to loading onto the instrument.

CD-MS. CD-MS measurements were performed on an Orbitrap Q Exactive UHMR mass spectrometer (Thermo Fisher Scientific). Samples were introduced into a gold-coated borosilicate capillary (prepared in-house) for nanoelectrospray ionization in positive ion mode. A resolution of 200000 at 400 $m / z$ was set for $1 \mathrm{~s}$ ion transient. The noise level parameter was fixed at 0 . Nitrogen was used as the collision gas. The insource-trapping voltage and HCD voltage were optimized for maximal ion transmission. After multiscan acquisition, .RAW files were centroided and converted into mzXML format for processing as previously described. ${ }^{39}$ A calibration factor of 12.55 (normalized arbitrary intensities/charges) was applied for correlating the measured intensities and charges of individual single ions. Several mzXML files could be merged to one for providing a larger number of statistics. According to the determined charge state, a resulting formula mass $=m / z \times$ $\mathrm{z}-\mathrm{z}$ was used to calculate the mass of each single ion, separately. Peaks for each mass species were determined using the kernel density estimation (KDE) maximum. All CD-MS histograms were plotted using $5 \mathrm{kDa}$ bin widths.

All samples for CD-MS measurements were first buffer exchanged into $500 \mathrm{mM}$ ammonium acetate solution ( $\mathrm{pH} 7.5$ ) using Amicon $10 \mathrm{kDa}$ MWCO centrifugal filters (Merck Millipore), unless otherwise stated. For IgG binding experiments, a $100 \mathrm{nM}$ solution of SARS-CoV-2 $\mathrm{S}$ protein was mixed with an equal volume of ligand to an excess ratio (4 Abs:1 Strimer) and incubated at room temperature $\left(22^{\circ} \mathrm{C}\right)$ for at least 5 min. Afterward, $\sim 3 \mu \mathrm{L}$ of the reaction mixture was introduced into the mass spectrometer for the measurement. For binding experiments containing both Abs and ACE2, S protein was preincubated with $\mathrm{Ab}$ for $5 \mathrm{~min}$ as described above, after which an equal volume of ACE2 solution at the desired concentration was added and incubated for a further 5 min prior to loading onto the instrument. For Fab binding experiments, a $1 \mu \mathrm{M}$ solution of SARS-CoV-2 S protein was mixed and preincubated with an equal volume of $\mathrm{Fab}$ to an excess ratio (5 Fabs:1 S-trimer) before buffer exchange into $500 \mathrm{mM}$ ammonium acetate solution $(\mathrm{pH} 7.5)$ using a micro Bio-Spin 6 column (Bio-Rad).

\section{ASSOCIATED CONTENT}

\section{(s) Supporting Information}

The Supporting Information is available free of charge at https://pubs.acs.org/doi/10.1021/acscentsci.1c00804.
Additional data, figures, and mass histograms with tabulations of binding stoichiometries and antibody characteristics (PDF)

\section{AUTHOR INFORMATION}

\section{Corresponding Author}

Albert J. R. Heck - Biomolecular Mass Spectrometry and Proteomics, Bijvoet Center for Biomolecular Research and Utrecht Institute for Pharmaceutical Sciences, Utrecht University, $3584 \mathrm{CH}$ Utrecht, The Netherlands; Netherlands Proteomics Center, $3584 \mathrm{CH}$ Utrecht, The Netherlands; ○ orcid.org/0000-0002-2405-4404; Email: a.j.r.heck@ uu.nl

\section{Authors}

Victor Yin - Biomolecular Mass Spectrometry and Proteomics, Bijvoet Center for Biomolecular Research and Utrecht Institute for Pharmaceutical Sciences, Utrecht University, $3584 \mathrm{CH}$ Utrecht, The Netherlands; Netherlands Proteomics Center, $3584 \mathrm{CH}$ Utrecht, The Netherlands; 1 orcid.org/ 0000-0003-0104-0293

Szu-Hsueh Lai - Biomolecular Mass Spectrometry and Proteomics, Bijvoet Center for Biomolecular Research and Utrecht Institute for Pharmaceutical Sciences, Utrecht University, $3584 \mathrm{CH}$ Utrecht, The Netherlands; Netherlands Proteomics Center, $3584 \mathrm{CH}$ Utrecht, The Netherlands

Tom G. Caniels - Department of Medical Microbiology and Infection Prevention, Amsterdam University Medical Centers, Location AMC, University of Amsterdam, 1105 AZ Amsterdam, The Netherlands

Philip J. M. Brouwer - Department of Medical Microbiology and Infection Prevention, Amsterdam University Medical Centers, Location AMC, University of Amsterdam, 1105 AZ Amsterdam, The Netherlands

Mitch Brinkkemper - Department of Medical Microbiology and Infection Prevention, Amsterdam University Medical Centers, Location AMC, University of Amsterdam, 1105 AZ Amsterdam, The Netherlands

Yoann Aldon - Department of Medical Microbiology and Infection Prevention, Amsterdam University Medical Centers, Location AMC, University of Amsterdam, 1105 AZ Amsterdam, The Netherlands

Hejun Liu - Department of Integrative Structural and Computational Biology, The Scripps Research Institute, La Jolla, California 92037, United States

Meng Yuan - Department of Integrative Structural and Computational Biology, The Scripps Research Institute, La Jolla, California 92037, United States

Ian A. Wilson - Department of Integrative Structural and Computational Biology and Skaggs Institute for Chemical Biology, The Scripps Research Institute, La Jolla, California 92037, United States

Rogier W. Sanders - Department of Medical Microbiology and Infection Prevention, Amsterdam University Medical Centers, Location AMC, University of Amsterdam, 1105 AZ Amsterdam, The Netherlands; Department of Microbiology and Immunology, Weill Medical College of Cornell University, New York, New York 10065, United States

Marit J. van Gils - Department of Medical Microbiology and Infection Prevention, Amsterdam University Medical Centers, Location AMC, University of Amsterdam, 1105 AZ Amsterdam, The Netherlands 
Complete contact information is available at:

https://pubs.acs.org/10.1021/acscentsci.1c00804

\section{Author Contributions \\ ${ }^{\nabla}$ V.Y. and S.-H.L. contributed equally. Project conception: V.Y., S.-H.L., R.W.S., M.J.v.G., and A.J.R.H. Protein synthesis: T.G.C., P.J.M.B., M.B., Y.A., H.L., and M.Y. Data collection: V.Y. and S.-H.L. Writing: V.Y., S.-H.L., R.W.S., M.J.v.G., I.A.W., and A.J.R.H. Supervision: I.A.W., R.W.S., M.J.v.G., and A.J.R.H. Editing/review: all authors.}

\section{Notes}

The authors declare the following competing financial interest(s): Amsterdam UMC filed a patent application on SARS-CoV-2 monoclonal antibodies including the ones used in this manuscript.

\section{ACKNOWLEDGMENTS}

This research received funding through the Dutch Research Council (NWO) funding The Netherlands Proteomics Centre through the X-omics Road Map program (project 184.034.019). A.J.R.H. acknowledges support from The Netherlands Organization for Scientific Research (NWO) through the Spinoza Award SPI.2017.028 to A.J.R.H. R.W.S. acknowledges support from The Netherlands Organization for Scientific Research (NWO) through a Vici grant. The authors also acknowledge support from the Bill \& Melinda Gates Foundation grants INV-002022 and INV-008818 (to R.W.S.), INV-024617 (M.J.v.G.), and INV-004923 (to I.A.W.). M.J.v.G. is a recipient of an Amsterdam UMC AMC Fellowship.

\section{REFERENCES}

(1) Zhu, N.; Zhang, D.; Wang, W.; Li, X.; Yang, B.; Song, J.; Zhao, X.; Huang, B.; Shi, W.; Lu, R.; Niu, P.; Zhan, F.; Ma, X.; Wang, D.; Xu, W.; Wu, G.; Gao, G. F.; Tan, W. A Novel Coronavirus from Patients with Pneumonia in China, 2019. N. Engl. J. Med. 2020, 382 (8), 727-733.

(2) Zhou, P.; Yang, X.-L.; Wang, X.-G.; Hu, B.; Zhang, L.; Zhang, W.; Si, H.-R.; Zhu, Y.; Li, B.; Huang, C.-L.; Chen, H.-D.; Chen, J.; Luo, Y.; Guo, H.; Jiang, R.-D.; Liu, M.-Q.; Chen, Y.; Shen, X.-R.; Wang, X.; Zheng, X.-S.; Zhao, K.; Chen, Q.-J.; Deng, F.; Liu, L.-L.; Yan, B.; Zhan, F.-X.; Wang, Y.-Y.; Xiao, G.-F.; Shi, Z.-L. A Pneumonia Outbreak Associated with a New Coronavirus of Probable Bat Origin. Nature 2020, 579 (7798), 270-273.

(3) Amanat, F.; Krammer, F. SARS-CoV-2 Vaccines: Status Report. Immunity 2020, 52 (4), 583-589.

(4) Hoffmann, M.; Kleine-Weber, H.; Schroeder, S.; Krüger, N.; Herrler, T.; Erichsen, S.; Schiergens, T. S.; Herrler, G.; Wu, N.-H.; Nitsche, A.; Müller, M. A.; Drosten, C.; Pöhlmann, S. SARS-CoV-2 Cell Entry Depends on ACE2 and TMPRSS2 and Is Blocked by a Clinically Proven Protease Inhibitor. Cell 2020, 181 (2), 271-280.

(5) Corbett, K. S.; Edwards, D. K.; Leist, S. R.; Abiona, O. M.; Boyoglu-Barnum, S.; Gillespie, R. A.; Himansu, S.; Schäfer, A.; Ziwawo, C. T.; DiPiazza, A. T.; Dinnon, K. H.; Elbashir, S. M.; Shaw, C. A.; Woods, A.; Fritch, E. J.; Martinez, D. R.; Bock, K. W.; Minai, M.; Nagata, B. M.; Hutchinson, G. B.; Wu, K.; Henry, C.; Bahl, K.; Garcia-Dominguez, D.; Ma, L.; Renzi, I.; Kong, W.-P.; Schmidt, S. D.; Wang, L.; Zhang, Y.; Phung, E.; Chang, L. A.; Loomis, R. J.; Altaras, N. E.; Narayanan, E.; Metkar, M.; Presnyak, V.; Liu, C.; Louder, M. K.; Shi, W.; Leung, K.; Yang, E. S.; West, A.; Gully, K. L.; Stevens, L. J.; Wang, N.; Wrapp, D.; Doria-Rose, N. A.; Stewart-Jones, G.; Bennett, H.; Alvarado, G. S.; Nason, M. C.; Ruckwardt, T. J.; McLellan, J. S.; Denison, M. R.; Chappell, J. D.; Moore, I. N.; Morabito, K. M.; Mascola, J. R.; Baric, R. S.; Carfi, A.; Graham, B. S. SARS-CoV-2 MRNA Vaccine Design Enabled by Prototype Pathogen Preparedness. Nature 2020, 586 (7830), 567-571.
(6) Sahin, U.; Muik, A.; Derhovanessian, E.; Vogler, I.; Kranz, L. M.; Vormehr, M.; Baum, A.; Pascal, K.; Quandt, J.; Maurus, D.; Brachtendorf, S.; Lörks, V.; Sikorski, J.; Hilker, R.; Becker, D.; Eller, A.-K.; Grützner, J.; Boesler, C.; Rosenbaum, C.; Kühnle, M.-C.; Luxemburger, U.; Kemmer-Brück, A.; Langer, D.; Bexon, M.; Bolte, S.; Karikó, K.; Palanche, T.; Fischer, B.; Schultz, A.; Shi, P.-Y.; FontesGarfias, C.; Perez, J. L.; Swanson, K. A.; Loschko, J.; Scully, I. L.; Cutler, M.; Kalina, W.; Kyratsous, C. A.; Cooper, D.; Dormitzer, P. R.; Jansen, K. U.; Türeci, Ö. COVID-19 Vaccine BNT162b1 Elicits Human Antibody and T H 1 T Cell Responses. Nature 2020, 586 (7830), 594-599.

(7) Watanabe, Y.; Mendonça, L.; Allen, E. R.; Howe, A.; Lee, M.; Allen, J. D.; Chawla, H.; Pulido, D.; Donnellan, F.; Davies, H.; Ulaszewska, M.; Belij-Rammerstorfer, S.; Morris, S.; Krebs, A.-S.; Dejnirattisai, W.; Mongkolsapaya, J.; Supasa, P.; Screaton, G. R.; Green, C. M.; Lambe, T.; Zhang, P.; Gilbert, S. C.; Crispin, M. Native-like SARS-CoV-2 Spike Glycoprotein Expressed by ChAdOx1 NCoV-19/AZD1222 Vaccine. ACS Cent. Sci. 2021, 7 (4), 594-602.

(8) Brouwer, P. J. M.; Brinkkemper, M.; Maisonnasse, P.; Dereuddre-Bosquet, N.; Grobben, M.; Claireaux, M.; Gast, M. de; Marlin, R.; Chesnais, V.; Diry, S.; Allen, J. D.; Watanabe, Y.; Giezen, J. M.; Kerster, G.; Turner, H. L.; Straten, K. v. d.; Linden, C. A. v. d.; Aldon, Y.; Naninck, T.; Bontjer, I.; Burger, J. A.; Poniman, M.; Mykytyn, A. Z.; Okba, N. M. A.; Schermer, E. E.; Breemen, M. J. v.; Ravichandran, R.; Caniels, T. G.; Schooten, J. v.; Kahlaoui, N.; Contreras, V.; Lemaître, J.; Chapon, C.; Fang, R. H. T.; Villaudy, J.; Sliepen, K.; Velden, Y. U. v. d.; Haagmans, B. L.; Bree, G. J. de; Ginoux, E.; Ward, A. B.; Crispin, M.; King, N. P.; Werf, S. v. d.; Gils, M. J. v.; Grand, R. L.; Sanders, R. W. Two-Component Spike Nanoparticle Vaccine Protects Macaques from SARS-CoV-2 Infection. Cell 2021, 184 (5), 1188-1200.

(9) Zost, S. J.; Gilchuk, P.; Case, J. B.; Binshtein, E.; Chen, R. E.; Nkolola, J. P.; Schäfer, A.; Reidy, J. X.; Trivette, A.; Nargi, R. S.; Sutton, R. E.; Suryadevara, N.; Martinez, D. R.; Williamson, L. E.; Chen, E. C.; Jones, T.; Day, S.; Myers, L.; Hassan, A. O.; Kafai, N. M.; Winkler, E. S.; Fox, J. M.; Shrihari, S.; Mueller, B. K.; Meiler, J.; Chandrashekar, A.; Mercado, N. B.; Steinhardt, J. J.; Ren, K.; Loo, Y.M.; Kallewaard, N. L.; McCune, B. T.; Keeler, S. P.; Holtzman, M. J.; Barouch, D. H.; Gralinski, L. E.; Baric, R. S.; Thackray, L. B.; Diamond, M. S.; Carnahan, R. H.; Crowe, J. E. Potently Neutralizing and Protective Human Antibodies against SARS-CoV-2. Nature 2020, 584 (7821), 443-449.

(10) Maisonnasse, P.; Aldon, Y.; Marc, A.; Marlin, R.; DereuddreBosquet, N.; Kuzmina, N.; Freyn, A.; Snitselaar, J.; Gonçalves, A.; Caniels, T.; Burger, J.; Poniman, M.; Bontjer, I.; Chesnais, V.; Diry, S.; Iershov, A.; Ronk, A.; Jangra, S.; Rathnasinghe, R.; Brouwer, P.; Bijl, T.; Schooten, J. v.; Brinkkemper, M.; Liu, H.; Yuan, M.; Mire, C.; Breemen, M. v.; Contreras, V.; Naninck, T.; Lemaitre, J.; Kahlaoui, N.; Relouzat, F.; Chapon, C.; Fang, R. H. T.; McDanal, C.; OseiTwum, M.; St-Amant, N.; Gagnon, L.; Montefiori, D.; Wilson, I.; Ginoux, E.; Bree, G. de; Garcia-Sastre, A.; Schotsaert, M.; Coughlan, L.; Bukreyev, A.; Werf, S. v. d.; Guedj, J.; Sanders, R.; Gils, M. v.; Le Grand, R. COVA1-18 Neutralizing Antibody Protects against SARSCoV-2 in Three Preclinical Models. Nat. Commun. 2021, 12 (1), 6097.

(11) Walls, A. C.; Park, Y.-J.; Tortorici, M. A.; Wall, A.; McGuire, A. T.; Veesler, D. Structure, Function, and Antigenicity of the SARSCoV-2 Spike Glycoprotein. Cell 2020, 181 (2), 281-292.

(12) Brouwer, P. J. M.; Caniels, T. G.; Straten, K. v. d.; Snitselaar, J. L.; Aldon, Y.; Bangaru, S.; Torres, J. L.; Okba, N. M. A.; Claireaux, M.; Kerster, G.; Bentlage, A. E. H.; Haaren, M. M. v.; Guerra, D.; Burger, J. A.; Schermer, E. E.; Verheul, K. D.; Velde, N. v. d.; Kooi, A. v. d.; Schooten, J. v.; Breemen, M. J. v.; Bijl, T. P. L.; Sliepen, K.; Aartse, A.; Derking, R.; Bontjer, I.; Kootstra, N. A.; Wiersinga, W. J.; Vidarsson, G.; Haagmans, B. L.; Ward, A. B.; Bree, G. J. de; Sanders, R. W.; Gils, M. J. v.. Potent Neutralizing Antibodies from COVID-19 Patients Define Multiple Targets of Vulnerability. Science 2020, 369 (6504), 643-650. 
(13) Ju, B.; Zhang, Q.; Ge, J.; Wang, R.; Sun, J.; Ge, X.; Yu, J.; Shan, S.; Zhou, B.; Song, S.; Tang, X.; Yu, J.; Lan, J.; Yuan, J.; Wang, H.; Zhao, J.; Zhang, S.; Wang, Y.; Shi, X.; Liu, L.; Zhao, J.; Wang, X.; Zhang, Z.; Zhang, L. Human Neutralizing Antibodies Elicited by SARS-CoV-2 Infection. Nature 2020, 584 (7819), 115-119.

(14) Shi, R.; Shan, C.; Duan, X.; Chen, Z.; Liu, P.; Song, J.; Song, T.; Bi, X.; Han, C.; Wu, L.; Gao, G.; Hu, X.; Zhang, Y.; Tong, Z.; Huang, W.; Liu, W. J.; Wu, G.; Zhang, B.; Wang, L.; Qi, J.; Feng, H.; Wang, F.-S.; Wang, Q.; Gao, G. F.; Yuan, Z.; Yan, J. A Human Neutralizing Antibody Targets the Receptor-Binding Site of SARS-CoV-2. Nature 2020, 584 (7819), 120-124.

(15) Bell, B. N.; Powell, A. E.; Rodriguez, C.; Cochran, J. R.; Kim, P. S. Neutralizing Antibodies Targeting the SARS-CoV-2 Receptor Binding Domain Isolated from a Naive Human Antibody Library. Protein Sci. 2021, 30 (4), 716-727.

(16) Rogers, T. F.; Zhao, F.; Huang, D.; Beutler, N.; Burns, A.; He, W.; Limbo, O.; Smith, C.; Song, G.; Woehl, J.; Yang, L.; Abbott, R. K.; Callaghan, S.; Garcia, E.; Hurtado, J.; Parren, M.; Peng, L.; Ramirez, S.; Ricketts, J.; Ricciardi, M. J.; Rawlings, S. A.; Wu, N. C.; Yuan, M.; Smith, D. M.; Nemazee, D.; Teijaro, J. R.; Voss, J. E.; Wilson, I. A.; Andrabi, R.; Briney, B.; Landais, E.; Sok, D.; Jardine, J. G.; Burton, D. R. Isolation of Potent SARS-CoV-2 Neutralizing Antibodies and Protection from Disease in a Small Animal Model. Science 2020, 369 (6506), 956.

(17) Xu, C.; Wang, Y.; Liu, C.; Zhang, C.; Han, W.; Hong, X.; Wang, Y.; Hong, Q.; Wang, S.; Zhao, Q.; Wang, Y.; Yang, Y.; Chen, K.; Zheng, W.; Kong, L.; Wang, F.; Zuo, Q.; Huang, Z.; Cong, Y. Conformational Dynamics of SARS-CoV-2 Trimeric Spike Glycoprotein in Complex with Receptor ACE2 Revealed by Cryo-EM. Sci. Adv. 2021, 7 (1), eabe5575.

(18) Lu, M.; Uchil, P. D.; Li, W.; Zheng, D.; Terry, D. S.; Gorman, J.; Shi, W.; Zhang, B.; Zhou, T.; Ding, S.; Gasser, R.; Prévost, J.; Beaudoin-Bussières, G.; Anand, S. P.; Laumaea, A.; Grover, J. R.; Liu, L.; Ho, D. D.; Mascola, J. R.; Finzi, A.; Kwong, P. D.; Blanchard, S. C.; Mothes, W. Real-Time Conformational Dynamics of SARS-CoV-2 Spikes on Virus Particles. Cell Host Microbe 2020, 28 (6), 880-891.

(19) Wu, N. C.; Yuan, M.; Bangaru, S.; Huang, D.; Zhu, X.; Lee, C.C. D.; Turner, H. L.; Peng, L.; Yang, L.; Burton, D. R.; Nemazee, D.; Ward, A. B.; Wilson, I. A. A Natural Mutation between SARS-CoV-2 and SARS-CoV Determines Neutralization by a Cross-Reactive Antibody. PLoS Pathog. 2020, 16 (12), e1009089.

(20) Bachmann, M. F.; Kalinke, U.; Althage, A.; Freer, G.; Burkhart, C.; Roost, H.-P.; Aguet, M.; Hengartner, H.; Zinkernagel, R. M. The Role of Antibody Concentration and Avidity in Antiviral Protection. Science 1997, 276 (5321), 2024-2027.

(21) Klein, J. S.; Bjorkman, P. J. Few and Far Between: How HIV May Be Evading Antibody Avidity. PLoS Pathog. 2010, 6 (5), e1000908.

(22) Green, R. J.; Frazier, R. A.; Shakesheff, K. M.; Davies, M. C.; Roberts, C. J.; Tendler, S. J. B. Surface Plasmon Resonance Analysis of Dynamic Biological Interactions with Biomaterials. Biomaterials 2000, 21 (18), 1823-1835.

(23) Abdiche, Y.; Malashock, D.; Pinkerton, A.; Pons, J. Determining Kinetics and Affinities of Protein Interactions Using a Parallel Real-Time Label-Free Biosensor, the Octet. Anal. Biochem. 2008, 377 (2), 209-217.

(24) Säfsten, P. Epitope Mapping by Surface Plasmon Resonance. In Epitope Mapping Protocols: Second ed.; Schutkowski, M., Reineke, U., Eds.; Methods in Molecular Biology; Humana Press: Totowa, NJ, 2009; pp 67-76. DOI: 10.1007/978-1-59745-450-6 5 .

(25) Bangaru, S.; Ozorowski, G.; Turner, H. L.; Antanasijevic, A.; Huang, D.; Wang, X.; Torres, J. L.; Diedrich, J. K.; Tian, J.-H.; Portnoff, A. D.; Patel, N.; Massare, M. J.; Yates, J. R.; Nemazee, D.; Paulson, J. C.; Glenn, G.; Smith, G.; Ward, A. B. Structural Analysis of Full-Length SARS-CoV-2 Spike Protein from an Advanced Vaccine Candidate. Science 2020, 370 (6520), 1089-1094.

(26) Liu, H.; Wu, N. C.; Yuan, M.; Bangaru, S.; Torres, J. L.; Caniels, T. G.; Schooten, J. v.; Zhu, X.; Lee, C.-C. D.; Brouwer, P. J. M.; Gils, M. J. v.; Sanders, R. W.; Ward, A. B.; Wilson, I. A. Cross-
Neutralization of a SARS-CoV-2 Antibody to a Functionally Conserved Site Is Mediated by Avidity. Immunity 2020, 53 (6), 1272-1280.

(27) Pinto, D.; Park, Y.-J.; Beltramello, M.; Walls, A. C.; Tortorici, M. A.; Bianchi, S.; Jaconi, S.; Culap, K.; Zatta, F.; Marco, A. D.; Peter, A.; Guarino, B.; Spreafico, R.; Cameroni, E.; Case, J. B.; Chen, R. E.; Havenar-Daughton, C.; Snell, G.; Telenti, A.; Virgin, H. W.; Lanzavecchia, A.; Diamond, M. S.; Fink, K.; Veesler, D.; Corti, D. Cross-Neutralization of SARS-CoV-2 by a Human Monoclonal SARSCoV Antibody. Nature 2020, 583 (7815), 290-295.

(28) Asarnow, D.; Wang, B.; Lee, W.-H.; Hu, Y.; Huang, C.-W.; Faust, B.; Ng, P. M. L.; Ngoh, E. Z. X.; Bohn, M.; Bulkley, D.; Pizzorno, A.; Ary, B.; Tan, H. C.; Lee, C. Y.; Minhat, R. A.; Terrier, O.; Soh, M. K.; Teo, F. J.; Yeap, Y. Y. C.; Seah, S. G. K.; Chan, C. E. Z.; Connelly, E.; Young, N. J.; Maurer-Stroh, S.; Renia, L.; Hanson, B. J.; Rosa-Calatrava, M.; Manglik, A.; Cheng, Y.; Craik, C. S.; Wang, C.I. Structural Insight into SARS-CoV-2 Neutralizing Antibodies and Modulation of Syncytia. Cell 2021, 184 (12), 3192-3204.

(29) Lan, J.; Ge, J.; Yu, J.; Shan, S.; Zhou, H.; Fan, S.; Zhang, Q.; Shi, X.; Wang, Q.; Zhang, L.; Wang, X. Structure of the SARS-CoV-2 Spike Receptor-Binding Domain Bound to the ACE2 Receptor. Nature 2020, 581 (7807), 215-220.

(30) Lenza, M. P.; Oyenarte, I.; Diercks, T.; Quintana, J. I.; Gimeno, A.; Coelho, H.; Diniz, A.; Peccati, F.; Delgado, S.; Bosch, A.; Valle, M.; Millet, O.; Abrescia, N. G. A.; Palazón, A.; Marcelo, F.; JiménezOsés, G.; Jiménez-Barbero, J.; Ardá, A.; Ereño-Orbea, J. Structural Characterization of N-Linked Glycans in the Receptor Binding Domain of the SARS-CoV-2 Spike Protein and Their Interactions with Human Lectins. Angew. Chem., Int. Ed. 2020, 59 (52), 2376323771.

(31) Heck, A. J. R. Native Mass Spectrometry: A Bridge between Interactomics and Structural Biology. Nat. Methods 2008, 5 (11), 927-933.

(32) Casalino, L.; Gaieb, Z.; Goldsmith, J. A.; Hjorth, C. K.; Dommer, A. C.; Harbison, A. M.; Fogarty, C. A.; Barros, E. P.; Taylor, B. C.; McLellan, J. S.; Fadda, E.; Amaro, R. E. Beyond Shielding: The Roles of Glycans in the SARS-CoV-2 Spike Protein. ACS Cent. Sci. 2020, 6 (10), 1722-1734.

(33) Watanabe, Y.; Allen, J. D.; Wrapp, D.; McLellan, J. S.; Crispin, M. Site-Specific Glycan Analysis of the SARS-CoV-2 Spike. Science 2020, 369 (6501), 330-333.

(34) Sanda, M.; Morrison, L.; Goldman, R. N- and O-Glycosylation of the SARS-CoV-2 Spike Protein. Anal. Chem. 2021, 93 (4), 20032009.

(35) Struwe, W. B.; Robinson, C. V. Relating Glycoprotein Structural Heterogeneity to Function - Insights from Native Mass Spectrometry. Curr. Opin. Struct. Biol. 2019, 58, 241-248.

(36) Struwe, W. B.; Stuckmann, A.; Behrens, A.-J.; Pagel, K.; Crispin, M. Global N-Glycan Site Occupancy of HIV-1 Gp120 by Metabolic Engineering and High-Resolution Intact Mass Spectrometry. ACS Chem. Biol. 2017, 12 (2), 357-361.

(37) Yang, Y.; Du, Y.; Kaltashov, I. A. The Utility of Native MS for Understanding the Mechanism of Action of Repurposed Therapeutics in COVID-19: Heparin as a Disruptor of the SARS-CoV-2 Interaction with Its Host Cell Receptor. Anal. Chem. 2020, 92 (16), 1093010934.

(38) Young, G.; Hundt, N.; Cole, D.; Fineberg, A.; Andrecka, J.; Tyler, A.; Olerinyova, A.; Ansari, A.; Marklund, E. G.; Collier, M. P.; Chandler, S. A.; Tkachenko, O.; Allen, J.; Crispin, M.; Billington, N.; Takagi, Y.; Sellers, J. R.; Eichmann, C.; Selenko, P.; Frey, L.; Riek, R.; Galpin, M. R.; Struwe, W. B.; Benesch, J. L. P.; Kukura, P. Quantitative Mass Imaging of Single Biological Macromolecules. Science 2018, 360 (6387), 423-427.

(39) Wörner, T. P.; Snijder, J.; Bennett, A.; Agbandje-McKenna, M.; Makarov, A. A.; Heck, A. J. R. Resolving Heterogeneous Macromolecular Assemblies by Orbitrap-Based Single-Particle Charge Detection Mass Spectrometry. Nat. Methods 2020, 17 (4), 395-398.

(40) Kafader, J. O.; Melani, R. D.; Durbin, K. R.; Ikwuagwu, B.; Early, B. P.; Fellers, R. T.; Beu, S. C.; Zabrouskov, V.; Makarov, A. A.; 
Maze, J. T.; Shinholt, D. L.; Yip, P. F.; Tullman-Ercek, D.; Senko, M. W.; Compton, P. D.; Kelleher, N. L. Multiplexed Mass Spectrometry of Individual Ions Improves Measurement of Proteoforms and Their Complexes. Nat. Methods 2020, 17 (4), 391-394.

(41) Soltermann, F.; Foley, E. D. B.; Pagnoni, V.; Galpin, M.; Benesch, J. L. P.; Kukura, P.; Struwe, W. B. Quantifying ProteinProtein Interactions by Molecular Counting with Mass Photometry. Angew. Chem., Int. Ed. 2020, 59 (27), 10774-10779.

(42) Keifer, D. Z.; Pierson, E. E.; Jarrold, M. F. Charge Detection Mass Spectrometry: Weighing Heavier Things. Analyst 2017, 142 (10), 1654-1671.

(43) Tamara, S.; den Boer, M. A.; Heck, A. J. R. High-Resolution Native Mass Spectrometry. Chem. Rev. 2021, DOI: 10.1021/ acs.chemrev.1c00212.

(44) Allen, J. D.; Chawla, H.; Samsudin, F.; Zuzic, L.; Shivgan, A. T.; Watanabe, Y.; He, W.-T.; Callaghan, S.; Song, G.; Yong, P.; Brouwer, P. J. M.; Song, Y.; Cai, Y.; Duyvesteyn, H. M. E.; Malinauskas, T.; Kint, J.; Pino, P.; Wurm, M. J.; Frank, M.; Chen, B.; Stuart, D. I.; Sanders, R. W.; Andrabi, R.; Burton, D. R.; Li, S.; Bond, P. J.; Crispin, M. Site-Specific Steric Control of SARS-CoV-2 Spike Glycosylation. Biochemistry 2021, 60, 2153-2169.

(45) Miller, L. M.; Barnes, L. F.; Raab, S. A.; Draper, B. E.; El-Baba, T. J.; Lutomski, C. A.; Robinson, C. V.; Clemmer, D. E.; Jarrold, M. F. Heterogeneity of Glycan Processing on Trimeric SARS-CoV-2 Spike Protein Revealed by Charge Detection Mass Spectrometry. J. Am. Chem. Soc. 2021, 143 (10), 3959-3966.

(46) Barnes, C. O.; West, A. P.; Huey-Tubman, K. E.; Hoffmann, M. A. G.; Sharaf, N. G.; Hoffman, P. R.; Koranda, N.; Gristick, H. B.; Gaebler, C.; Muecksch, F.; Lorenzi, J. C. C.; Finkin, S.; Hägglöf, T.; Hurley, A.; Millard, K. G.; Weisblum, Y.; Schmidt, F.; Hatziioannou, T.; Bieniasz, P. D.; Caskey, M.; Robbiani, D. F.; Nussenzweig, M. C.; Bjorkman, P. J. Structures of Human Antibodies Bound to SARSCoV-2 Spike Reveal Common Epitopes and Recurrent Features of Antibodies. Cell 2020, 182 (4), 828-842.

(47) Yan, R.; Wang, R.; Ju, B.; Yu, J.; Zhang, Y.; Liu, N.; Wang, J.; Zhang, Q.; Chen, P.; Zhou, B.; Li, Y.; Shen, Y.; Zhang, S.; Tian, L.; Guo, Y.; Xia, L.; Zhong, X.; Cheng, L.; Ge, X.; Zhao, J.; Wang, H.-W.; Wang, X.; Zhang, Z.; Zhang, L.; Zhou, Q. Structural Basis for Bivalent Binding and Inhibition of SARS-CoV-2 Infection by Human Potent Neutralizing Antibodies. Cell Res. 2021, 31 (5), 517-525.

(48) Liu, H.; Yuan, M.; Huang, D.; Bangaru, S.; Zhao, F.; Lee, C.-C. D.; Peng, L.; Barman, S.; Zhu, X.; Nemazee, D.; Burton, D. R.; van Gils, M. J.; Sanders, R. W.; Kornau, H.-C.; Reincke, S. M.; Prüss, H.; Kreye, J.; Wu, N. C.; Ward, A. B.; Wilson, I. A. A Combination of Cross-Neutralizing Antibodies Synergizes to Prevent SARS-CoV-2 and SARS-CoV Pseudovirus Infection. Cell Host Microbe 2021, 29 (5), 806-818

(49) Cho, H.; Gonzales-Wartz, K. K.; Huang, D.; Yuan, M.; Peterson, M.; Liang, J.; Beutler, N.; Torres, J. L.; Cong, Y.; Postnikova, E.; Bangaru, S.; Talana, C. A.; Shi, W.; Yang, E. S.; Zhang, Y.; Leung, K.; Wang, L.; Peng, L.; Skinner, J.; Li, S.; Wu, N. C.; Liu, H.; Dacon, C.; Moyer, T.; Cohen, M.; Zhao, M.; Lee, F. E.H.; Weinberg, R. S.; Douagi, I.; Gross, R.; Schmaljohn, C.; Pegu, A.; Mascola, J. R.; Holbrook, M.; Nemazee, D.; Rogers, T. F.; Ward, A. B.; Wilson, I. A.; Crompton, P. D.; Tan, J. Ultrapotent Bispecific Antibodies Neutralize Emerging SARS-CoV-2 Variants. bioRxiv preprint, 2021, 2021.04.01.437942. DOI: 10.1101/2021.04.01.437942.

(50) Yuan, M.; Huang, D.; Lee, C.-C. D.; Wu, N. C.; Jackson, A. M.; Zhu, X.; Liu, H.; Peng, L.; Gils, M. J. v.; Sanders, R. W.; Burton, D. R.; Reincke, S. M.; Prüss, H.; Kreye, J.; Nemazee, D.; Ward, A. B.; Wilson, I. A. Structural and Functional Ramifications of Antigenic Drift in Recent SARS-CoV-2 Variants. Science 2021, 373, 818.

(51) Yang, T.-J.; Yu, P.-Y.; Chang, Y.-C.; Liang, K.-H.; Tso, H.-C.; Ho, M.-R.; Chen, W.-Y.; Lin, H.-T.; Wu, H.-C.; Hsu, S.-T. D. Effect of SARS-CoV-2 B.1.1.7 Mutations on Spike Protein Structure and Function. Nat. Struct. Mol. Biol. 2021, 28, 731.

(52) Starr, T. N.; Greaney, A. J.; Addetia, A.; Hannon, W. W.; Choudhary, M. C.; Dingens, A. S.; Li, J. Z.; Bloom, J. D. Prospective
Mapping of Viral Mutations That Escape Antibodies Used to Treat COVID-19. Science 2021, 371 (6531), 850-854.

(53) Wang, P.; Nair, M. S.; Liu, L.; Iketani, S.; Luo, Y.; Guo, Y.; Wang, M.; Yu, J.; Zhang, B.; Kwong, P. D.; Graham, B. S.; Mascola, J. R.; Chang, J. Y.; Yin, M. T.; Sobieszczyk, M.; Kyratsous, C. A.; Shapiro, L.; Sheng, Z.; Huang, Y.; Ho, D. D. Antibody Resistance of SARS-CoV-2 Variants B.1.351 and B.1.1.7. Nature 2021, 593 (7857), $130-135$.

(54) Wibmer, C. K.; Ayres, F.; Hermanus, T.; Madzivhandila, M.; Kgagudi, P.; Oosthuysen, B.; Lambson, B. E.; de Oliveira, T.; Vermeulen, M.; van der Berg, K.; Rossouw, T.; Boswell, M.; Ueckermann, V.; Meiring, S.; von Gottberg, A.; Cohen, C.; Morris, L.; Bhiman, J. N.; Moore, P. L. SARS-CoV-2 501Y.V2 Escapes Neutralization by South African COVID-19 Donor Plasma. Nat. Med. 2021, 27 (4), 622-625.

(55) Caniels, T. G.; Bontjer, I.; Straten, K. v. d.; Poniman, M.; Burger, J. A.; Appelman, B.; Lavell, A. H. A.; Oomen, M.; Godeke, G.J.; Valle, C.; Moegling, R.; Willigen, H. D. G. v.; Wynberg, E.; Schinkel, M.; Vught, L. A. v.; Guerra, D.; Snitselaar, J. L.; Chaturbhuj, D. N.; Martin, I. C.; Moore, J. P.; Jong, M. D. de; Reusken, C.; Sikkens, J. J.; Bomers, M. K.; Bree, G. J. de; Gils, M. J. v.; Eggink, D.; Sanders, R. W. Emerging SARS-CoV-2 Variants of Concern Evade Humoral Immune Responses from Infection and Vaccination. Sci. Adv. 2021, 7 (36), eabj5365.

(56) Baum, A.; Fulton, B. O.; Wloga, E.; Copin, R.; Pascal, K. E.; Russo, V.; Giordano, S.; Lanza, K.; Negron, N.; Ni, M.; Wei, Y.; Atwal, G. S.; Murphy, A. J.; Stahl, N.; Yancopoulos, G. D.; Kyratsous, C. A. Antibody Cocktail to SARS-CoV-2 Spike Protein Prevents Rapid Mutational Escape Seen with Individual Antibodies. Science 2020, 369 (6506), 1014-1018.

(57) Koenig, P.-A.; Das, H.; Liu, H.; Kümmerer, B. M.; Gohr, F. N.; Jenster, L.-M.; Schiffelers, L. D. J.; Tesfamariam, Y. M.; Uchima, M.; Wuerth, J. D.; Gatterdam, K.; Ruetalo, N.; Christensen, M. H.; Fandrey, C. I.; Normann, S.; Tödtmann, J. M. P.; Pritzl, S.; Hanke, L.; Boos, J.; Yuan, M.; Zhu, X.; Schmid-Burgk, J. L.; Kato, H.; Schindler, M.; Wilson, I. A.; Geyer, M.; Ludwig, K. U.; Hällberg, B. M.; Wu, N. C.; Schmidt, F. I. Structure-Guided Multivalent Nanobodies Block SARS-CoV-2 Infection and Suppress Mutational Escape. Science 2021, 371 (6530), eabe6230.

(58) Rose, R. J.; Labrijn, A. F.; van den Bremer, E. T. J.; Loverix, S.; Lasters, I.; van Berkel, P. H. C.; van de Winkel, J. G. J.; Schuurman, J.; Parren, P. W. H. I.; Heck, A. J. R. Quantitative Analysis of the Interaction Strength and Dynamics of Human IgG4 Half Molecules by Native Mass Spectrometry. Structure 2011, 19 (9), 1274-1282.

(59) Virtanen, P.; Gommers, R.; Oliphant, T. E.; Haberland, M.; Reddy, T.; Cournapeau, D.; Burovski, E.; Peterson, P.; Weckesser, W.; Bright, J.; van der Walt, S. J.; Brett, M.; Wilson, J.; Millman, K. J.; Mayorov, N.; Nelson, A. R. J.; Jones, E.; Kern, R.; Larson, E.; Carey, C. J.; Polat, I.; Feng, Y.; Moore, E. W.; VanderPlas, J.; Laxalde, D.; Perktold, J.; Cimrman, R.; Henriksen, I.; Quintero, E. A.; Harris, C. R.; Archibald, A. M.; Ribeiro, A. H.; Pedregosa, F.; van Mulbregt, P. SciPy 1.0: Fundamental Algorithms for Scientific Computing in Python. Nat. Methods 2020, 17 (3), 261-272. 